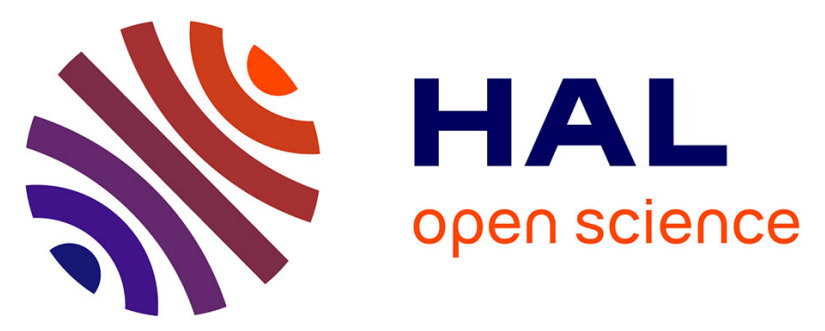

\title{
Investigating anhedonia in a non-conventional species: Do some riding horses Equus caballus display symptoms of depression?
}

Carole Fureix, Cleo Beaulieu, Soizic Argaud, Céline Rochais, Margaret Quinton, Séverine Henry, Martine Hausberger, Georgia Mason

\section{To cite this version:}

Carole Fureix, Cleo Beaulieu, Soizic Argaud, Céline Rochais, Margaret Quinton, et al.. Investigating anhedonia in a non-conventional species: Do some riding horses Equus caballus display symptoms of depression?. Applied Animal Behaviour Science, 2015, 162, pp.26 - 36. 10.1016/j.applanim.2014.11.007 . hal-01101485

HAL Id: hal-01101485

https://hal-univ-rennes1.archives-ouvertes.fr/hal-01101485

Submitted on 9 Jan 2015

HAL is a multi-disciplinary open access archive for the deposit and dissemination of scientific research documents, whether they are published or not. The documents may come from teaching and research institutions in France or abroad, or from public or private research centers.
L'archive ouverte pluridisciplinaire HAL, est destinée au dépôt et à la diffusion de documents scientifiques de niveau recherche, publiés ou non, émanant des établissements d'enseignement et de recherche français ou étrangers, des laboratoires publics ou privés. 


\section{Investigating anhedonia in a non-conventional species: do some riding}

2 horses Equus caballus display symptoms of depression?

3

4 Carole Fureix $^{\mathrm{a}}$, Cleo Beaulieu ${ }^{\mathrm{a}}$, Soizic Argaud ${ }^{\mathrm{b}}$, Céline Rochais $^{\mathrm{c}}$, Margaret Quinton ${ }^{\mathrm{a}}$, Séverine

5 Henry $^{\mathrm{c}}$, Martine Hausberger ${ }^{\mathrm{b}, \mathrm{c}}$, Georgia Mason $^{\mathrm{a}^{*}}$

6

$7^{\text {a }}$ Department of Animal and Poultry Science, University of Guelph, 50 Stone Road $8 \quad$ East $\square$ Guelph, Ontario, N1G 2W1, Canada

$9 \quad$ b CNRS UMR 6552 Ethologie Animale et Humaine, Université Rennes 1 Bâtiment 25, Campus 10 de Beaulieu, 263 Avenue du General Leclerc, CS 74205, 35042 Rennes Cedex, France

$11{ }^{c}$ Université Rennes 1 UMR CNRS 6552 Ethologie Animale et Humaine, Station Biologique 12 de Paimpont, 35380, Paimpont, France

14 * corresponding author: g.mason@uoguelph.ca Tel.: +44-0117-928-9485

\footnotetext{
${ }^{1}$ Present address: Centre for Behavioural Biology, Department of Clinical Veterinary Science, University of Bristol, Langford House, Langford BS40 5DU, UK
} 
Investigating depression-like conditions in animals is methodologically challenging, but potentially important for welfare. Some riding horses display 'withdrawn' states of inactivity and low responsiveness that resemble the reduced engagement with the environment shown by certain depressed patients. To assess whether these animals are experiencing a depression-like state, we investigated anhedonia -- the loss of pleasure, a key symptom of human depression - in 20 withdrawn and non-withdrawn horses from the same stable. The time horses spent being withdrawn appeared unrelated to age or sex, but correlated with time devoted to stereotypic behaviour, a possible marker of lifetime stress. Comparison with data collected 5 years earlier also revealed that horses scored as withdrawn then remained significantly likely to display the behaviour. We measured sucrose intake, a classic measure of anhedonia never previously applied to horses. Flavoured sugar blocks, novel to these subjects, were mounted in each stall and weighed $3 \mathrm{~h}, 8 \mathrm{~h}, 24 \mathrm{~h}$ and $30 \mathrm{~h}$ after provision. We predicted that if affected by depressionlike states, the most withdrawn horses would consume the least sucrose. This prediction was met $\left(\mathrm{F}_{1,18}=4.65\right.$, two tailed $\left.\mathrm{p}=0.04\right)$. This pattern could, however, potentially reflect general appetite levels and/or food neophobia. To control for these confounds, hay consumption was measured over 5 days, as were subjects' latencies to eat a meal scented with a novel odour. Although low hay consumption and long latencies to eat scented food did predict low sucrose consumption, statistically controlling for these confounds did not eliminate the relationship between being withdrawn and consuming less sucrose (although reducing it to a strong trend): $\mathrm{F}_{1,15}=4.28$, two-tailed $\mathrm{p}=0.056$. These data thus suggest long-lasting depression-like states in certain riding horses, which correlate with stereotypic behaviour and are characterised by anhedonia and bouts of 'withdrawn' unresponsiveness. 
39 Key-words: horses; depression; anhedonia; depression-like conditions; reduced engagement

40 with environment; DSM-V 
In humans, clinical depression -- by which we mean "major depressive disorder" or the experience of "depressive episodes", to encompass DSM-V (Diagnostic Manual of Mental Disorders- fifth edition, American Psychiatric Association APA, 2013) and ICD-10 (International Statistical Classification of Diseases and Related Health Problems, World Health Organisation WHO, 1994) terminologies - is a common mental illness (e.g. annual prevalence in the U.S.: $7 \%$ of the population, APA, 2013), especially in women. It is a complex, phenotypically heterogeneous syndrome, clinically diagnosed by the co-occurrence of a variety of affective, cognitive and behavioural symptoms (Table 1) that include low, hopeless moods, "not caring", social withdrawal, and fatigue (APA, 2013). These are present for many days or weeks, and interfere with abilities to cope with everyday life. Related phenomena supporting diagnosis include anxiety, tearfulness, obsessive rumination, brooding, and complaints of aches and pains (APA, 2013), with one study further highlighting "nonspecific gaze, withdrawal, [no mouth movements, and], no eye region movement" as behavioural markers of the condition (Schelde, 1998). Additional attributes common in clinically depressed humans - although not reliable, specific or sensitive enough for use in diagnosis (APA, 2013) - include alterations of the hypothalamic-pituitary-adrenal (HPA) axis (both elevations ${ }^{\text {e.g. }}$ Miller et al., 2007, and subnormal levels ${ }^{\text {e.g. }}$ Strickland et al., 2002).

In terms of aetiology, a common trigger is chronic stress, for instance that arising from aversive life events or chronic pain or illness (e.g. Banks and Kerns, 1996; Blackburn-Munro and Blackburn-Munro, 2001; Tafet and Bernardini, 2003; Munce et al., 2006; Siegrist, 2008; Hammen et al., 2009; APA, 2013). Two types of cognitive change can often be observed before the illness fully develops, and these may act as mediators in some subjects, being hypothesised to help cause the onset and/or maintenance of the disease (Beck, 1967; Gotlib and 
desired outcomes are believed improbable or highly aversive outcomes are believed probable, and the individual comes to expect that no response in his repertoire will change their likelihood" (Abramson et al., 1978). The second involves negative biases in attention, memory and/or judgment (Beck, 1967; MacLeod and Byrne, 1996; Gotlib and Krasnoperova, 1998). Thus depressed people are prone for example, to judge ambiguous stimuli as being unlikely to be positive ('cognitive pessimism'), and to recall unpleasant memories more readily than pleasant ones.

The symptoms of depression may not be unique to humans. A Web of Science literature search using the terms "rats" OR "mice" OR "monkeys" AND "depression" yielded over 100,000 articles: laboratory rodents in particular are widely used to model clinical depression, primarily to screen drugs for human use (reviewed in e.g. Matthews et al., 2005; Deussing, 2006). Although "it is exceedingly difficult to envision an animal model that perfectly recapitulates the symptoms of depression in human patients" (Deussing, 2006), much of this animal work does appear to validly model at least some symptoms of this disease. For an animal condition to be deemed homologous to a human illness, it must display several forms of validity (Belzung and Lemoine, 2011; Camus et al., 2013a): symptoms should seem analogous to those of affected humans (sometimes called "face validity"); the animal's condition should mimic the human disease in terms of risk, protective and therapeutic factors (sometimes called "predictive validity"); and underlying mechanisms should ideally be homologous (although for depression, this would require a consensus about its mechanistic bases that does not currently exist, see ${ }^{\text {e.g. }}$ Moore, 2002; Strickland et al., 2002). By exposing laboratory animals to chronic unpredictable stress - as well as to lesions, drugs and genetic manipulations that arguably have less predictive validity (Deussing, 2006) - researchers have successfully induced responses 
unavoidable stressors ( ${ }^{e . g .}$ Maier and Seligman, 1976), along with anhedonia (e.g. Willner et al., 1992), a reduction in pleasure that we discuss in detail below.

Furthermore, outside of this type of research environment, circumstantial evidence has led several authors to hypothesise that depression-like states occur in other animals. Pet dogs and cats have been suggested to show "depressed behaviour" when deprived of their owners (Fox, 1968, p. 357), as have apes housed long-term in barren environments in laboratories or zoos (e.g. Engel, 2002 p174, Brune et al., 2006; Ferdowsian et al., 2011; Hennessy et al., 2014) and maternally deprived monkeys (e.g. Harlow and Suomi, 1974; Suomi et al., 1975; Hennessy et al., 2014). Horses, too, have been suggested to sometimes display depression-like symptoms (Pritchard et al., 2005; Hall et al., 2008; Burn et al., 2010; Fureix et al., 2012; Popescu and Diugan, 2013). States involving profound inactivity and low responsiveness to external stimuli have thus been reported in working equids in the developing world (Swann, 2006; Burn et al., 2010), and in riding horses in Europe and North America (Fureix et al., 2012). For example, Hall and colleagues describe riding school horses "who seem to have 'switched off' (are unresponsive, lack motivation, and are apathetic)". Recently, data have been collected to describe such horses' characteristics more formally. Fureix et al. (2012) found that 'withdrawn' states are characterised by a stationary, atypical, flat-necked posture (Figure 1); wide open, unblinking eyes with an apparently fixed gaze; and backwards-pointing ears. Even when not engaged in these unusual behaviours, horses with these states differed from non-withdrawn horses from the same stable in several ways: they show reduced responsiveness to tactile stimulation; less reaction to a human's sudden appearance at the stall door; less exploration and more behavioural signs of arousal (fear) when exposed to a novel object; and lower baseline levels of plasma cortisol. Furthermore, while the full aetiology of such states is still unclear, being withdrawn was more prevalent in female riding horses than male (Fureix et al., 2012); inactivity combined with low responsiveness to external stimuli is, in working equids, 
associated with illness and advanced age (Burn et al., 2010); and, more speculatively, sustained adversity has been hypothesised to play a role. Thus Hall et al. (2008) suggested that "apathetic and lethargic" horses have generally been "stabled for the majority of their lives with no opportunity for social interaction", with such responses reflecting stress-induced "learned helplessness" (see also Ödberg, 1987). Fureix et al. (2012) therefore hypothesised, by analogy with human clinical depression, that withdrawn horses exhibit a depression-like state.

We chose to test this hypothesis empirically for horses, by assessing face validity more years (Feighner et al., 1972), anhedonia has been a diagnostic criterion since DSM-III (APA, 1980), and is now seen as one of the condition's most important symptoms (WHO, 1994; APA, 2013; Table 1). In animals, anhedonia has been successfully modelled in biomedical studies of rodents, primarily via inducing and recording reductions in sucrose intake (e.g. Papp et al., 1991; Willner et al., 1992; Forbes et al., 1996; Brennan et al., 2001; Deussing, 2006; Walker and Mason, 2011). Evidence that this sucrose-ingestion is pleasure-driven includes that rodents will some recreational drugs (e.g. Lowe and Butryn, 2007; Olsen, 2011; Pratt et al., 2012); and that in rats the frequency of $50 \mathrm{KHz}$ ultrasonic vocalisations (typically produced when anticipating positive reinforcers; Knutson et al., 2002) correlates positively with preferences for sweet food (Mateus-Pinheiro et al., 2014). That reduced sucrose intake by rodents is a symptom of depression-like anhedonia has been further validated by its induction by chronic stressors (e.g. Papp et al., 1991; Willner et al., 1992; Gronli et al., 2005); its alleviation by anti-depressant drugs (e.g. Muscat et al., 1992; Nestler et al., 2002; Deussing, 2006; McArthur and Borsini, 2006; Malatynska et al., 2012); and its co-variation with other depression-like features 139 including learned helplessness (e.g. Strekalova et al., 2004) and negative cognitive biases 
140 (Rygula et al., 2013). Like rodents, horses reportedly prefer sucrose solutions to water (Randall et al., 1978), and often choose sweetened food over unsweetened (Hawkes et al., 1985). We therefore chose to assess reduced sucrose intakes as a measure of anhedonia in horses.

This work thus aimed to use this measure to test the hypothesis that withdrawn horses are experiencing a depression-like condition. Using withdrawn and non-withdrawn horses from the same riding stable, we predicted that, if in depression-like states, withdrawn horses would consume less sucrose than non-withdrawn stable-mates. To both refine this experiment and better characterise the withdrawn state, we also assessed some additional variables. Most of our subjects had been screened for withdrawn states five years previously (Fureix et al., 2012); we therefore opportunistically investigated whether individuals displaying withdrawn postures in 2007 would still be prone now. In the absence of direct information on the types of aversive early life experience and stressful life events that predispose humans to depression (e.g. Gilmer and McKinney, 2003; Tafet and Bernardini, 2003; Siegrist, 2008), we also assessed our subjects' levels of stereotypic behaviour. In populations with diverse past experiences, and/or stressful lives since (Lutz et al., 2003; Mason and Latham, 2004; Jones et al., 2011; Gottlieb et al., 2013). Assuming this holds for horses, we used stereotypic behaviour as a proxy measure of individuals' life stress, predicting positive relationships between it and the display withdrawn behaviour and sucrose intake. The first was general appetite at the time of test: checking that general feed consumption levels do not explain sucrose consumption is an important control in rodent and primate biomedical studies of anhedonia ( ${ }^{e . g .}$ Willner et al., 
novel to the subjects (see Methods); withdrawn horses appear to react to novelty more strongly than non-withdrawn horses (Fureix et al., 2012); and in laboratory mice, neophobia increases the latency with which mice ingest solid sugar placed in their cages, independently of anhedonia (Walker and Mason, 2011). We predicted that if in depression-like states, withdrawn horses should still consume less sucrose than non-withdrawn horses even after statistically accounting for these two potential confounds. The third potential confound was withdrawn horses not noticing the offered sucrose because engaged in bouts of non-responsiveness. We therefore assessed sucrose consumption in the first 3 hours after presentation, to check that both withdrawn and non-withdrawn horses sampled it within that short time.

\section{METHODS}

\subsection{Ethical note}

This study was approved by the University of Guelph Animal Care Committee (Animal

Utilization Protocol number: 2023) and complied with the Canadian Council on Animal Care guidelines, French laws related to animal experimentation and the European directive 86/609/CEE. Horse husbandry and care were under management of the riding school: the horses used in this experiment were not research animals.

\subsection{Subjects}

Twenty horses -16 geldings and 4 mares, aged 7 to 20 years old (on average $14.5 \pm 3.9$ ) five years previously (Fureix et al., 2012) (Table 2). All came from a single riding school located in western France, at which they had been housed for at least a year. The sample 
included 17 French Saddlebreds, one French Trotter plus one Anglo-Arabian (two breeds

191

192 originally involved in the creation of the French Saddlebred breed) and one unregistered horse (thus of unknown breed). Each was kept singly in $3 \mathrm{~m}$ x $3 \mathrm{~m}$ individual straw-bedded stall in a barn, allowing visual contact with conspecifics. Each stall was cleaned every morning, and was equipped with an automatic drinker. Animals were fed hay (6-7kg) once daily (13:00h), and commercial pellets three times daily $(07: 00 \mathrm{~h}, 12: 00 \mathrm{~h}, 19: 00 \mathrm{~h})$. These pellets were composed of wheat bran, $(30 \%)$, barley $(28 \%)$, alfalfa flour $(10 \%)$, palm kernels $(10 \%)$, soya beans $(10 \%)$, oats $(6 \%)$, and trace amounts of treacle, corn, calcium carbonate, sodium chloride, vitamins A, D, E and copper sulphate. The horses worked in riding lessons for 4 to 12 hours a week, with two rest days per week during which they were released in groups into paddocks. Riding lessons involved children and teenagers, and both indoor (instruction) and outdoor activities, including a few competitions.

\subsection{Behavioural recording: withdrawn status and stereotypic behaviour}

The time each horse spent being withdrawn in its stall was determined by a single trained observer, using instantaneous scan sampling (Martin and Bateson, 2007) every 2 minutes over $1 \mathrm{~h}$ long periods, repeated daily over 15 days. Sampling sessions were conducted during daylight, at 06:00h, 07:00h, 10:00h, 11:00h, 15:00h, 16:00h, 20:00h and 21:00h. The silent observer (CB) walked regularly along the corridor and observations were made at a distance of $3 \mathrm{~m}$. The average number of total scans obtained per subject was $907 \pm 11.14$ (horses were sometimes away from their stall, e.g. for lessons, resulting in variation in observation number). All behaviours were recorded (see ${ }^{e . g}$. Waring, 2003 for a detailed ethogram), but we only report here only the states of interest for this study, i.e. the time spent being withdrawn, along with stereotypic behaviour (crib-biting, tongue and lips movements, weaving, head shaking and nodding; descriptions in Table 3; see also ${ }^{\text {e.g. }}$ Hausberger et al., 2009; Fureix et 

follows: the horse was standing motionless, with eyes open but unblinking, without ear or head movements, and displaying a stretched neck (i.e. obtuse jaw-neck angle) and a similar height

218 between neck and back (i.e. a nape-withers-back angle of $180^{\circ}$ ) (see also Fig 1). A horse displaying all of the above-mentioned characteristics, but blinking the eyes or moving the ears once, was scored as "moderately withdrawn". We chose to do so due to a lack of control over aspects of the environment, such as very windy weather or unpredictable loud noises in the stable, that could potentially very briefly disrupt withdrawn states by inducing a very brief ear movement or eye blinking (therefore violating, although very briefly, the withdrawn definition criteria). Spending time fully withdrawn was extremely strongly related to spending time moderately withdrawn (see Results), supporting a posteriori our assumption that the two measures reflected the same state, and we therefore pooled the two measures in the ethogram for further analyses. Note that sensu stricto instantaneous scan sampling was unsuitable for identifying withdrawn states, which were characterised by a lack of movement, and for stereotypic behaviours characterised by repetition. In such instances, the observer switched to focal observation, the activity of the horse of interest being continuously observed for $15 \mathrm{~s}$ (see e.g. Mason, 1993 and Tilly et al., 2010 for a similar mixture of focal and instantaneous scan sampling).

\subsection{Sucrose intake measurement}

Over the six days prior to the study, all horses were offered $10 \mathrm{~g}$ of raw sugar (lumps) once a day, presented by the observer directly under the nostrils, palm up. All horses consumed sugar lumps, revealing no spontaneous aversion towards sucrose in any of the subjects (see ${ }^{e . g}$. Hawkes et al., 1985 for evidence that sucrose consumption is common but not universal in horses). On the first day of the experiment, flavoured sucrose blocks (600g, Likit@, UK), all 
novel to these horses, were presented under the nostrils of each subject until one lick occurred, and then immediately mounted on the wall of each stall like a salt block. To measure rates of sucrose intake, these sugar blocks were weighed $3 \mathrm{~h}, 8 \mathrm{~h}, 24 \mathrm{~h}$ and $30 \mathrm{~h}$ after provision (initial time of block mounting: between 09:00 and 11:00). The 30h long testing period covered both pre- and post-meals intervals, allowing us to control for alliesthesia (modulation of the rewarding value of food according to whether in a deprived or satiated state, Booth et al., 1972; Thompson et al., 1976). To control for possible individual variation in flavour preference (known in horses, Goodwin et al., 2005), the test was replicated three times in succession, using three different Likit ${ }^{\circledR}$ flavours (cherry, banana and apple). Flavour order was pseudo-randomly assigned to control for effects of presentation order.

\subsection{Hay consumption and the "novel meal" experiment}

All subjects' total hay consumption over a 5 day period was measured to estimate overall food consumption level. Hay nets containing the usual rations were weighed daily prefeeding (at 13:00h) and after $3 \mathrm{~h}$ of exposure. Any fallen hay was collected from the bedding and placed back in the hay net prior to each weighing. To assess neophobia towards novel foods, horses' latencies to eat a meal of their usual pellets that had been scented with a mixture of unfamiliar aromatics (10g of aromatic herbs "Herbes de Provence" and $10 \mathrm{ml} \mathrm{cl}$ of a solution “Arôme Fleur d'Oranger", Vahiné() were then measured. Long latencies to interact with a novel object are typically interpreted as reflecting higher levels of anxiety or neophobia (e.g. Wolff et al., 1997; Ennaceur et al., 2005). The aromatics and their concentrations were chosen after pilot observations performed on five other horses from the same stable (not study subjects) ensured that the novel flavour in food was perceptible (e.g. inducing sniffing) to horses. Meal delivery was performed by the horses' usual caretaker, following the normal daily routine but with an experimenter by her side. The experimenter for this part was SA, not $\mathrm{CB}$, and blind to 
all horses' results from any other test/observation. Horses were tested one at a time, counterbalanced according to their withdrawn status (i.e. testing equal proportions of withdrawn and non-withdrawn horses) across time periods within a day (meal at 07:00h, 12:00h am or 19:00h) and over testing days. The experimenter began to record time immediately after the caretaker poured the pellets into the feeding trough, stopping immediately after the horse took two consecutive mouthfuls without any intervening behaviour other than chewing and swallowing. This caretaker was also blind to the aims of the study, being told that only horses' behaviours were being recorded for further analyses, and asked to behave in her usual way. Each tested horse's latency to eat a normal meal of usual pellets was also recorded (once per horse).

\subsection{Statistical analyses}

Data collected to test our hypothesis' main prediction were the percentage of time each horse spent being withdrawn and the cumulative proportion of sugar consumed from the Likit ${ }^{\circledR}$ $600 \mathrm{~g}$ blocks after $3 \mathrm{~h}, 8 \mathrm{~h}, 24 \mathrm{~h}$ and $30 \mathrm{~h}$ of exposure, averaging the "cherry", "banana" and "apple" replicates. Data which were not hypothesized to be markers of depression-like conditions per se but instead were informative about chronic stress and/or allowed us to rule out potential confounds were: hay consumption ( $\mathrm{kg}$ ) over 5 days; latencies ( $\mathrm{s}$ ) to eat a meal of normal pellets scented with novel aromatics; and the percentage of time each horse spent in

For the fifteen subjects categorised five years previously as withdrawn or not (Fureix et al., 2012), we assessed whether they still fell into the same categories (displaying at least one withdrawn bout or never observed being withdrawn) using a Fisher's Exact test (Graphpad: http://graphpad.com/quickcalcs/contingency1.cfm). 
Cary, NC, USA) (using an alpha of 0.05 , and two-tailed tests) to investigate relationships between time spent in withdrawn states (controlling for age and sex) and sugar consumption and stereotypic behaviour; and between time spent in withdrawn behaviour and age and sex.

Normality and homogeneity of variances were assessed by inspection of residuals (Grafen and Hails, 2002), and Shapiro-Wilk W tests. For these, and the subsequent models using SAS, proportional data were always arcsinsquareroot transformed (Doncaster and Davey, 2007, p16) to fit the parametric assumptions of GLMs.

The relationship between the time each horse spent being withdrawn and sucrose intake was investigated using the following repeated measures mixed GLM (Model 1), accounting for horse within sex as a random effect: sugar eaten $=$ horse $($ sex $)+$ weighing time $(3,8,24,30 \mathrm{~h}$ after provision) + time spent withdrawn + age + sex + time each horse spent in its stall during testing. The time each horse spent in its stall was included because horses removed from their stall for lessons obviously could not ingest sugar during those periods. The Brown and Forsythe (modified Levene) test was used to compare the variances between treatment groups for all variables prior to analysis, and showed no evidence of heterogeneity for any variable. Models were run using the mixed procedure in SAS (version 9.3), and repeated measures were handled according to the method given by Wang and Goonewardene (2004). The Akaike (1974) criterion was used to determine the best fitting covariance structure among the repeated measurements over time on the same horse, and the error degrees of freedom for hypothesis testing was calculated using a Satterthwaite approximation. Residual plots were examined after the analysis, and showed no evidence of any associations with means (or non-homogeneity of variances).

Because this model revealed a significant relationship between withdrawn behaviour and sucrose intake (see Results), both hay consumption and latency to eat the novel-scented 
food were then added as to the model as additional controls (Model 2). Because stereotypic behaviour co-varied with time spent withdrawn (see Results), one final repeated measures model (with additional controls as Model 2) was conducted to assess whether stereotypic behaviour per se predicted sucrose consumption. If it did not, any relationship between anhedonia and withdrawn states could not be causally related to stereotypic behaviour (while if it did, a model including both stereotypic behaviour and time spent being withdrawn as predictors would be necessary in order to identify the best predictor of sucrose consumption).

\section{RESULTS}

Our subjects spent far more time being moderately withdrawn than fully withdrawn (fully: $0.050 \pm 0.11 \%$ time, range $0-0.40$; moderately: $0.67+/-0.95 \%$ time, range $0-0.29$ ). However, spending time fully withdrawn was extremely strongly related to spending time moderately withdrawn $\left(\mathrm{F}_{1,16}=31.66, \mathrm{p}<0.0001\right)$, and we therefore pooled the two measures. The overall total proportion of time spent withdrawn (full + moderate) varied between 0 and $3.1 \%$ of observation time $(\mathrm{X}=0.72 \pm 1.05)$, with nine animals never displaying the behaviour. Horses that had been classified as withdrawn in 2007 were significantly more likely to display withdrawn behaviour in this study (Fisher's exact test, two-tailed: $p=0.041$ ). The time spent withdrawn was unaffected by horse age $\left(\mathrm{F}_{1,17}=0.011, \mathrm{p}=0.917\right)$ or $\operatorname{sex}\left(\mathrm{F}_{1,17}=1.346, \mathrm{p}=\right.$ $0.262)$, but was strongly related to the time $(X=1.68 \pm 4.27 \%$ time, $0-18 \%)$ devoted to stereotypic behaviour $\left(\mathrm{F}_{1,16}=9.404, \mathrm{p}=0.007\right)$.

In the Likit ${ }^{\circledR}$ ingestion tests, all but one horse ate the sugar (inferred from the weight of the block declining over time in a stall). Eighty per cent of subjects began to eat within the first $3 \mathrm{~h}$ of exposure; the other $20 \%$ comprised two withdrawn and two non-withdrawn horses. 
Withdrawn horses thus did not seem less likely to perceive the Likit® block. Furthermore, as predicted, horses spending the most time withdrawn showed less sucrose intake (Model 1: $\mathrm{F}_{1,18}$ $=4.65, \mathrm{p}=0.04)($ Fig 2$)$.

The potential confounds of general appetite and food neophobia were then investigated. Total hay intake over five days varied from 19 to $34 \mathrm{~kg}$ per horse $(\mathrm{X}=25.61 \pm 3.56)$. $A$ posteriori comparisons confirmed longer latencies to eat the pellet meal scented with novel aromatics $(\mathrm{X}=10.5 \mathrm{~s} \pm 9.6,1-42 \mathrm{~s})$ than the usual meal $(\mathrm{X}=1.8 \mathrm{~s} \pm 0.41,1-2 \mathrm{~s})$ (matched-pair $\mathrm{t}$ test, $\left.\mathrm{t}_{19}=4.08, \mathrm{p}<0.001\right)$, showing that horses did perceive the novel-scented meal as unfamiliar. Since latencies to eat the usual meal were all very short, never exceeding $2 \mathrm{~s}$, and showed negligible variation between horses, all further analyses use the raw latencies to eat the novel meal. When included in the repeated measures analysis (Model 2), low hay consumption was found to predict low sucrose intake $\left(\mathrm{F}_{1,14}=4.52, \mathrm{p}=0.051\right)$, as did long latencies to eat the novel-scented food $\left(\mathrm{F}_{1,14}=8.34, \mathrm{p}=0.012\right)$. However, statistically controlling for these two confounds did not eliminate the previous negative relationship between spending time withdrawn and eating sucrose $(\mathbf{F i g} 3)$, although reducing it to a strong trend $\left(\mathrm{F}_{1,15}=4.28, \mathrm{p}=\right.$ $0.056)$.

Stereotypic behaviour, in contrast, did not predict sucrose consumption $\left(\mathrm{F}_{1,15}=0.780\right.$, $\mathrm{p}=0.3916)$, despite being a strong correlate of time spent withdrawn.

\section{DISCUSSION}

As reviewed in the Introduction, our hypothesis that certain horses display depression-like states (e.g. Swann, 2006; Hall et al., 2008; Burn et al., 2010; Fureix et al., 2012) was based on apparent similarities between their reduced responsiveness and the reduced interactiveness of 
some depressed human patients; evidence of associated anxiety, which would support a diagnosis of depression in humans; hypocortisolaemia, as found in a sub-set of depressed humans; and some preliminary signs of predictive validity (greater occurrence in females and individuals suffering ill-health). To this, we now add evidence of a symptom that has strong face validity with a DSM-V diagnostic criterion, and that has been successfully used in biomedical research on depression-like states in rodents. Assuming that sucrose consumption in horses is driven by pleasure, as in humans and rodents (Jarosz et al., 2006; Lowe and Butryn, 2007; Olsen, 2011; Pratt et al., 2012), then horses that display states of withdrawn reduced reactivity are more anhedonic than those that do not. Such loss of pleasure is a key symptom of clinical depression, and suggests that withdrawn horses are indeed in a depression-like state. Our data also revealed that tendencies to be withdrawn, like clinical depression, are possibly long-lasting: many of our subjects classified as withdrawn five years earlier still displayed withdrawn behaviour now (although we cannot say whether their withdrawn behaviours occurred persistently over that time). Furthermore, these withdrawn states covaried with stereotypic behaviour. If individual differences in equine stereotypic behaviour reflect the number and severity of aversive past experiences (as in primates: see Introduction), this cautiously suggests that withdrawn states do likewise: an important hypothesis to test more fully in the future since, if supported, it would add to evidence of aetiological similarities between withdrawn states in horses and depressed states in humans.

All these findings still do not demonstrate with certainty that horses in human care can become clinically depressed: the quality and quantity of current evidence are not yet sufficient to conclude this. However, these data are sufficiently consistent with this hypothesis to make additional research very worthwhile, especially into the breadth and depth of anhedonia in affected horses, the existence of other key symptoms listed by the DSM, and the factors that trigger or reverse the appearance of withdrawn states. Given the range of species and number 
of individuals it has been suggested may be affected - not just horses but also captive primates and perhaps even pet dogs and cats - the welfare implications of animal depression provide a clear rationale for conducting such research. To end we therefore discuss how future research into animal depression might progress, starting with the assessment of pleasure and its loss.

We chose to assess anhedonia via sucrose consumption because of its successful, valid application in laboratory rodents, and ease of use for horses (important in a busy commercial riding stable). Despite these advantages, however, our approach had two drawbacks. The first is that a reduced interest in sugar is not, on its own, a symptom of clinical depression: anhedonia refers to a "markedly diminished ... pleasure in all, or almost all, activities" (APA, 2013; our emphasis). To demonstrate generalised anhedonia, the performance of a range of activities motivated by positive affect must therefore be observed: perhaps affiliative behaviours with preferred social partners (Ferdowsian et al., 2011), sexual behaviour (Gronli et al., 2005; Olsen, 2011), or interest in cues from potential mates (Finger et al., 2011). A second drawback was that our assumption that horses' sucrose ingestion is motivated by pleasure is untested. Both problems highlight a broader issue: how little is still known about positive affective states and hedonic motivations in almost all animal species (Boissy et al., 2007; Yeates and Main, 2008; Mellor, 2012). Potential future tools for identifying such behaviours include their response to naloxone - pleasure-motivated activities are more suppressed by opioid-antagonists than are activities motivated by need (Van Ree et al., 2000; Boissy et al., 2007; Lowe and Butryn, 2007) - and their response to deprivation: hedonically-motivated behaviours seem more driven by opportunism and external stimuli (i.e. eliciting cues such as odours) than by states of deprivation, while need-based behaviours are more sensitive to degrees of satiety or physiological deficit (Fraser and Duncan, 1998).

Along with assessing anhedonia more fully in potentially depressed animals, a further research need is to operationalise additional symptoms of depression for application to non- 
humans. Diagnoses of clinical depression in humans require the presence of at least five of the symptoms listed in Table 1, including anhedonia and/or low mood, plus evidence that they are debilitating. We agree with Ferdowsian et al. (2011) in their recent discussion of depressionlike states in captive chimpanzees, that the DSM represents a clear, objective way to diagnose depression in animals, but that two of its criteria (those pertaining to guilt and suicidality: items 7 and 9 in Table 1) are not operationalisable in non-humans. We also argue that a third, psychomotor retardation or agitation (item 5), should not be applied to animals, because identifying the former relies on speech, while the latter could be confused with stereotypic behaviour: definitively not a symptom of human depression. This leaves six symptoms (including anhedonia), of which five must be observed to trigger a diagnosis if DSM procedures are followed: low mood (1); changes in weight and/or appetite (3) insomnia/hypersomnia (4); fatigue or loss of energy (6); and reduced attentional, cognitive or decision-making abilities (8). If conducted carefully and critically, all could be objectively quantified in animals. To assess low mood, a particularly important feature of depression whose affective nature could make assessment challenging, we suggest assessing 'irritability' (e.g. unprovoked aggressive acts to conspecifics), as well as negative cognitive biases, such as pessimistic interpretations of ambiguous scenarios that closely relate to low moods in clinically depressed people (Beck, 1967; MacLeod and Byrne, 1996; Gotlib and Krasnoperova, 1998), and that can be assessed in animals (Harding et al., 2004; Mendl et al., 2009). As for evidence of dysfunction or impairment, valid measures in animals might include reduced attractiveness to potential mates (cf. Diez-Leon et al., 2013) and/or inadequate maternal care (Meagher et al., 2012). The third crucial avenue of research is to investigate predictive validity: the aetiology and response to therapeutic agents of depression-like conditions in horses and other animals. Since aversive early life experiences and stressful life events act as risk factors in humans (e.g. 439 Gilmer and McKinney, 2003; Tafet and Bernardini, 2003; Siegrist, 2008), they might therefore 
440 do so in animals (see ${ }^{\text {e.g. }}$ Camus et al., 2013b). In working horses, variables to investigate should 441 include weaning age/practices (e.g. Visser et al., 2008); time spent in isolation (e.g. McGreevy et 442 al., 1995; Cooper et al., 2000); painful conditions like vertebral problems (e.g. McGreevy and 443 McLean, 2005; Hausberger et al., 2009; Lesimple et al., 2010); and exposure to stressful 444 working conditions (e.g. Hausberger et al., 2009; Lesimple et al., 2010; Hausberger et al., 2011). 445 How depression-like states in animals respond to social support, anti-depressant drugs and 446 reduced stress should also be investigated. Such work would not only fully test the predictive 447 validity of depression-like states in animals (cf. Belzung and Lemoine, 2011), but also have significant welfare implications by revealing how we can we best prevent and treat such states.

\section{CONCLUSION}

452

Animals in human care sometimes display states of unresponsive inactivity after known or suspected chronic stress, pain or social isolation, leading to suggestions that they are 'depressed'. Testing such hypotheses is important for animal welfare. We propose that depression-like states in animals could be objectively identified using some of the diagnostic criteria relied on by human clinicians. Our findings that riding horses that display bouts of withdrawn inactivity (along with other depression-like changes) also consume less sucrose under test, suggest that these animals are anhedonic. We urge for more research into the assessment of pleasure and its loss in non-human animals.

\section{ACKNOWLEDGMENTS}

The authors are grateful to the director of the riding school and the staff for allowing us to work with their horses and their help and understanding. This work was supported by a 
466 Fyssen Foundation postdoctoral fellowship (to CF), a grant from the French Canada Research 467 Fund (held by GJM and MH), and a grant from the Caisse Centrale de la Mutualité Sociale

468

469

470

471

472

473

474

475

476

477

478

479

480

481

482

483

484

485

486

487

488

489

490

Agricole (to $\mathrm{MH}$ ). Additional support came from an NSERC Discovery to GJM. The funders

had no role in the study design, data collection and analyses, decision to publish or preparation of the manuscript. The authors report no conflicts of interest. We thanks two anonymous referees for their comments on the manuscript.

\section{REFERENCES}

Abramson, L.Y., Seligman, M.E.P., Teasdale, J.D., 1978. Learned helplessness in humans critique and reformulation. J. Abnorm. Psychol. 87, 49-74. DOI: 10.1037//0021843X.87.1.49

Akaike, H., 1974. A new look at the statistical model identification. IEEE Trans. Automat. Contr. AC19, 716-723.

APA, 1980. Diagnostic and Statistical Manual of Mental Disorders, third edition. American Psychiatric Association, Washington DC.

APA, 2013. Diagnostic and Statistical Manual of Mental Disorders, fifth edition. American Psychiatric Association, Arlington, VA.

Banks, S.M., Kerns, R.D., 1996. Explaining high rates of depression in chronic pain: A diathesis-stress framework. Psychol. Bull. 119, 95-110. DOI: 10.1037/00332909.119.1.95

Beck, A.T., 1967. Depression: Clinical, experimental and theoretical aspects. Harper and Row, New York.

Belzung, C., Lemoine, M., 2011. Criteria of validity for animal models of psychiatric disorders: focus on anxiety disorders and depression. Biology of Mood \& Anxiety Disorders 1, http://www.biolmoodanxietydisord.com/content/1/1/9. 
Blackburn-Munro, G., Blackburn-Munro, R.E., 2001. Chronic pain, chronic stress and depression: Coincidence or consequence? J. Neuroendocrinol. 13, 1009-1023. DOI: 10.1046/j.0007-1331.2001.00727.x

Boissy, A., Manteuffel, G., Jensen, M.B., Moe, R.O., Spruijt, B., Keeling, L.J., Winckler, C., Forkman, B., Dimitrov, I., Langbein, J., Bakken, M., Veissier, I., Aubert, A., 2007. Assessment of positive emotions in animals to improve their welfare. Physiol. Behav. 92, 375-397. DOI: 10.1016/j.physbeh.2007.02.003

Booth, D.A., Lovett, D., McSherry, G.M., 1972. Postingestive modulation of sweetness preference gradient in rat. J. Comp. Physiol. Psychol. 78, 485-512.

Brennan, K., Roberts, D.C.S., Anisman, H., Merali, Z., 2001. Individual differences in sucrose consumption in the rat: motivational and neurochemical correlates of hedonia. Psychopharmacology 157, 269-276.

Brune, M., Brune-Cohrs, U., McGrew, W.C., Preuschoft, S., 2006. Psychopathology in great apes: Concepts, treatment options and possible homologies to human psychiatric disorders. Neuroscience and Biobehavioral Reviews 30, 1246-1259.

Burn, C.C., Dennison, T.L., Whay, H.R., 2010. Relationships between behaviour and health in working horses, donkeys, and mules in developing countries. Appl. Anim. Behav. Sci. 126, 109-118. DOI: 10.1016/j.applanim.2010.06.007

Camus, S.M.J., Blois-Heulin, C., Li, Q., Hausberger, M., Bezard, E., 2013a. Behavioural profiles in captive- bred cynomolgus macaques: towards monkey models of mental disorders? PloS one 8, e62141. DOI: 10.1371/journal.pone.0062141

Camus, S.M.J., Rochais, C., Blois-Heulin, C., Li, Q., Hausberger, M., Bezard, E., 2013b. Birth origin differentially affects depressive- like behaviours: are captive- born cynomolgus monkeys more vulnerable to depression than their wild- born counterparts? PloS one 8, e67711. DOI: 10.1371/journal.pone.0067711 
516 Cooper, J.J., McDonald, L., Mills, D.S., 2000. The effect of increasing visual horizons on 517 stereotypic weaving : implications for the social housing of stabled horses. Appl. Anim. Behav. Sci. 69, 67-83. DOI: 10.1016/S0168-1591(00)00115-5

Deussing, J.M., 2006. Animal models of depression. Drug discovery today: disease models 3, 375-383. DOI: 10.1016/j.ddmod.2006.11.003

Diez-Leon, M., Bowman, J., Bursian, S., Filion, H., Galicia, D., Kanefsky, J., Napolitano, A., Palme, R., Schulte-Hostedde, A., Scribner, K., Mason, G., 2013. Environmentally Enriched Male Mink Gain More Copulations than Stereotypic, Barren-Reared Competitors. Plos One 8, e80494. DOI: 10.1371/journal.pone.0080494

Doncaster, C.P., Davey, A.J.H., 2007. Analysis of variance and covariance - How to choose and construct models for the life sciences. Cambridge University Press, Cambridge.

Engel, C., 2002. Wild health - How animals keep themselves well and what we can learn from them. Weidenfeld and Nicolson, London.

Ennaceur, A., Michalikova, S., Bradford, A., Ahmed, S., 2005. Detailed analysis of the behavior of Lister and Wistar rats in anxiety, object recognition and object location tasks. Behav. Brain Res. 159, 247-266. DOI: 10.1016/j.bbr.2004.11.006

Feighner, J.P., Robins, E., Guze, S.B., Woodruff, R.A., Winokur, G., Munoz, R., 1972. Diagnostic Criteria for Use in Psychiatric Research. Arch. Gen. Psychiatry 26(1), 57-63. DOI:10.1001/archpsyc.1972.01750190059011.

Ferdowsian, H.R., Durham, D.L., Kimwele, C., Kranendonk, G., Otali, E., Akugizibwe, T., Mulcahy, J.B., Ajarova, L., Johnson, C.M., 2011. Signs of Mood and Anxiety Disorders in Chimpanzees. Plos One 6, e19855. DOI: 10.1371/journal.pone.0019855

Finger, B.C., Dinan, T.G., Cryan, J.F., 2011. High-fat diet selectively protects against the effect of chronic social stress in the mouse. Neuroscience 192, 351-360. DOI: 10.1016/j.neuroscience.2011.06.072 
541 Forbes, N.F., Stewart, C.A., Matthews, K., Reid, I.C., 1996. Chronic mild stress and sucrose consumption: Validity as a model of depression. Physiol. Behav. 60, 1481-1484. DOI: 10.1016/S0031-9384(96)00305-8

544 Fox, M.W., 1968. Abnormal behavior in animals. W.B. Saunders Company, Philadelphia.

545 Fraser, D., Duncan, I.J.H., 1998. 'Pleasures','pains' and animal welfare: Toward a natural 546 history of affect. Animal Welfare 7, 383-396.

547 Fureix, C., Gorecka-Bruzda, A., Gautier, E., Hausberger, M., 2011a. Co-occurrence of yawning and stereotypic behaviour in horses Equus caballus. ISRN Zool., ID 271209. DOI:10.5402/2011/271209

Fureix, C., Hausberger, M., Seneque, E., Morisset, S., Baylac, M., Cornette, R., Biquand, V., Deleporte, P., 2011b. Geometric morphometrics for ethologists: improving the comparative study of behavioural postures. Naturwissenschaften 98, 583-592. DOI $10.1007 / \mathrm{s} 00114-011-0803-2$

Fureix, C., Jego, P., Henry, S., Lansade, L., Hausberger, M., 2012. Towards an Ethological Animal Model of Depression? A Study on Horses. Plos One 7, e39280. DOI: 10.1371/journal.pone.0039280

557

558

559

560

561

562

Gilmer, W.S., McKinney, W.T., 2003. Early experience and depressive disorders: human and non-human primate studies. J Affect. Disord. 75, 97-113. DOI: 10.1016/S01650327(03)00046-6

Goodwin, D., Davidson, H.P.B., Harris, P., 2005. Selection and acceptance of flavours in concentrate diets for stabled horses. Appl. Anim. Behav. Sci. 95, 223-232. DOI: 10.1016/j.applanim.2005.04.007

563

Gotlib, I.H., Krasnoperova, E., 1998. Biased information processing as a vulnerability factor for depression. Behavior Therapy 29, 603-617. DOI: 10.1016/S0005-7894(98)80020-8 
565 Gottlieb, D.H., Capitanio, J.P., McCowan, B., 2013. Risk factors for stereotypic behavior and self-biting in rhesus macaques (Macaca mulatta): Animal's history, current environment, and personality. Am. J. Primatol. 75, 995-1008. DOI: 10.1002/ajp.22161

Grafen, A., Hails, R., 2002. Modern Statistics for the Life Sciences. Oxford Univ. Press Inc., New York, NY.

570

571

572

573

574

575

576

577

578

579

580

581

582

583

584

585

586

587

588

Gronli, J., Murison, R., Fiske, E., Bjorvatn, B., Sorensen, E., Portas, C.M., Ursin, R., 2005. Effects of chronic mild stress on sexual behavior, locomotor activity and consumption of sucrose and saccharine solutions. Physiol. Behav. 84, 571-577. DOI: 10.1016/j.physbeh.2005.02.007

Hall, C., Goodwin, D., Heleski, C., Randle, H., Waran, N., 2008. Is there evidence of learned helplessness in horses? Appl. Anim. Welf. Sci. 11, 249-266. DOI: $10.1080 / 10888700802101130$

Hammen, C., Kim, E.Y., Eberhart, N.K., Brennan, P.A., 2009. Chronic and acute stress and the prediction of major depression in women. Depress. Anxiety. 26, 718-723. DOI: $10.1002 /$ da. 20571

Harding, E., Paul, E., Mendl, M., 2004. Cognitive bias and affective state. Nature 427, 312312. DOI: $10.1038 / 427312 \mathrm{a}$

Harlow, H., Suomi, S., 1974. Induced Depression in Monkeys. Behav. Biol. 12. DOI: 10.1016/S0091-6773(74)91475-8

Hausberger, M., Gautier, E., Biquand, V., Lunel, C., Jego, P., 2009. Could work be a source of behavioural disorders? A study in horses. PloS ONE 4, e7625. DOI: 10.1371/journal.pone.0007625

Hausberger, M., Muller, C., Lunel, C., 2011. Does Work Affect Personality? A Study in Horses. Plos One 6, e14659. DOI: 10.1371/journal.pone.0014659 
589 Hawkes, J., Hedges, M., Daniluk, P., Hintz, H.F., Schryver, H.F., 1985. Feed preferences of 590 ponies. Equine Vet. J. 17, 20-22.

591

592

593

594

595

596

597

598

599

600

601

602

603

604

605

606

607

608

609

610

611

612

Hennessy, M.B., McCowan, B., Jiang, J., Capitanio, J.P., 2014. Depressive-like behavioral response of adult male rhesus monkeys during routine animal husbandry procedure. Front. Behav. Neurosci. 8:309. DOI: 10.3389/fnbeh.2014.00309

Jarosz, P.A., Sekhon, P., Coscina, D.V., 2006. Effect of opioid antagonism on conditioned place preferences to snack foods. Pharmacology Biochemistry and Behavior 83, 257264. DOI: $10.1016 /$ j.pbb.2006.02.004

Jones, M.A., Mason, G., Pillay, N., 2011. Early environmental enrichment protects captiveborn striped mice against the later development of stereotypic behaviour. Appl. Anim. Behav. Sci. 135, 138- 145. DOI: 10.1016/j.applanim.2011.08.015

Knutson, B., Burgdorf, J., Panksepp, J., 2002. Ultrasonic Vocalizations as indices of affective states in rats. Psychol. Bull. 128, 961-977. DOI: 10.1037//0033-2909.128.6.961

Lesimple, C., Fureix, C., Menguy, H., Hausberger, M., 2010. Human Direct Actions May Alter Animal Welfare, a Study on Horses (Equus caballus). Plos One 5, e10257. DOI: 10.1371/journal.pone.0010257

Lowe, M.R., Butryn, M.L., 2007. Hedonic hunger: A new dimension of appetite? Physiol. Behav. 91, 432-439. DOI: 10.1016/j.physbeh.2007.04.006

Lutz, C., Well, A., Novak, M., 2003. Stereotypic and self-injurious behavior in rhesus macaques: A survey and retrospective analysis of environment and early experience. Am. J. Primatol. 60, 1-15. DOI: 10.1002/ajp.10075

MacLeod, A.K., Byrne, A., 1996. Anxiety, depression, and the anticipation of future positive and negative experiences. J. Abnorm. Psychol. 105, 286-289. DOI: 10.1037/0021843X.105.2.286 
613 Maier, S.F., Seligman, M.E.P., 1976. Learned helplessness - Theory and evidence. J. Exp. Psychol. Gen .105, 3-46. DOI: 10.1037/0096-3445.105.1.3

615

616

617

618

619

620

621

622

623

624

625

626

627

628

629

630

631

632

633

634

635

636

637

Malatynska, E., Steinbusch, H.W.M., Redkozubova, O., Bolkunov, A., Kubatiev, A., Yeritsyan, N.B., Vignisse, J., Bachurin, S., Strekalova, T., 2012. Anhedonic-like traits and lack of affective deficits in 18-month-old C57BL/6 mice: Implications for modeling elderly depression. Exp. Gerontol. 47, 552-564. DOI: 10.1016/j.exger.2012.04.010

Martin, P., Bateson, P., 2007. Measuring behaviour: an introductory guide. Third edition. Cambridge University Press, Cambridge.

Mason, G.J., 1993. Age and context affect the stereotypies of caged mink. Behav. 127, 191229. DOI: $10.1163 / 156853993 X 00029$

Mason, G.J., Latham, N.R., 2004. Can't stop, won't stop: is stereotypy a reliable animal welfare indicator? Animal welfare 13, 57-69.

Mateus-Pinheiro, A., Patricio, P., Alves, N.D., Machado-Santos, A.R., Morais, M., Bessa, J.M., Sousa, N., Pinto, L., 2014. The Sweet Drive Test: refining phenotypic characterization of anhedonic behavior in rodents. Front. Behav. Neurosci. 8:74. DOI: 10.3389/fnbeh.2014.00074

Matthews, K., Christmas, D., Swan, J., Sorrell, E., 2005. Animal Models of Depression and Antidepressant Activity. Neurosci. Biobehav. Rev. 29, 503-513. DOI:10.1016/j.neubiorev.2005.03.005

McArthur, R., Borsini, F., 2006. Animal models of depression in drug discovery: A historical perspective. Pharmacology Biochemistry and Behavior 84, 436-452. DOI: 10.1016/j.pbb.2006.06.005

McGreevy, P., McLean, A., 2005. Behavioural problems with the ridden horse, in: Mills, D.S., McDonnell, S.M. (Eds.), The Domestic Horse, The Origins, Development and Management of its Behaviour, Cambridge University Press, Cambridge, pp. 196-211. 
McGreevy, P.D., Cripps, P.J., French, N.P., Green, L.E., Nicol, C.J., 1995. Management factors associated with stereotypic and redirected behavior in the thoroughbred horse. Equine Vet J. 27, 86-91. http://dx.doi.org/10.1016/S0168-1591(02)00096-5

Meagher, R.K., Bechard, A., Mason, G.J., 2012. Mink with Divergent Activity Levels have Divergent Reproductive Strategies. Ethology 118, 543-554. DOI: 10.1111/j.14390310.2012.02044.x

Mellor, D.J., 2012. Animal emotions, behaviour and the promotion of positive welfare states. New Zealand Veterinary Journal 60, 1-8. DOI: 10.1080/00480169.2011.619047

Mendl, M., Burman, O.H.P., Parker, R.M.A., Paul, E.S., 2009. Cognitive bias as an indicator of animal emotion and welfare: Emerging evidence and underlying mechanisms. Appl. Anim. Behav. Sci. 118, 161-181. DOI: 10.1016/j.applanim.2009.02.023

Miller, G.E., Chen, E., Zhou, E.S., 2007. If it goes up, must it come down? Chronic stress and the hypothalamic-pituitary-adrenocortical axis in humans. Psychol. Bull. 133, 25-45. DOI: $10.1037 / 0033-2909.133 .1 .25$

Moore, B., 2002. Cortisol, stress and depression. Br. J. Psychiatry 181, 348-348. DOI: 10.1192/bjp.181.4.348

Munce, S.E.P., Weller, I., Blackmore, E.K.R., Heinmaa, M., Katz, J., Stewart, D.E., 2006. The role of work stress as a moderating variable in the chronic pain and depression association. J. Psychosom. Res. 61, 653-660. DOI: 10.1016/j.jpsychores.2006.03.048

Muscat, R., Papp, M., Willner, P., 1992. Reversal of stress-induced anhedonia by the atypical antidepressants, fluoxetine and maprotiline. Psychopharmacology 109, 433-438. DOI: 10.1007/BF02247719

Nestler, E., Gould, E., Manji, H., 2002. Preclinical models: status of basic research in depression. Biol. Psychiatry 52, 503-528. DOI: 10.1016/S0006-3223(02)01405-1

Ödberg, F.O., 1987. Chronic stress in riding horses. Equine Veterinary Journal 19, 268-269. 
663 Olsen, C.M., 2011. Natural rewards, neuroplasticity, and non-drug addictions.

664

665

666

667

668

669

670

671

672

673

674

675

676

677

678

679

680

681

682

683

684

685

686

Neuropharmacology 61, 1109-1122. DOI: 10.1016/j.neuropharm.2011.03.010

Papp, M., Willner, P., Muscat, R., 1991. An animal model of anhedonia - Attenuation of sucrose consumption and place preference conditioning by chronic unpredictable mild stress. Psychopharmacology 104, 255-259. DOI: 10.1007/BF02244188

Paul, I.A., English, J.A., Halaris, A., 2000. Sucrose and quinine intake by maternally-deprived and control rhesus monkeys. Behav. Brain Res. 112, 127-134. DOI: 10.1016/S01664328(00)00173-X

Popescu, S., Diugan, E.A., 2013. The Relationship Between Behavioral and Other Welfare Indicators of Working Horses. J. Equine Vet. Sci. 33, 1-12. DOI: 10.1016/j.jevs.2012.04.001

Pratt, W.E., Choi, E., Guy, E.G., 2012. An examination of the effects of subthalamic nucleus inhibition or mu-opioid receptor stimulation on food-directed motivation in the nondeprived rat. Behav. Brain Res. 230, 365-373. DOI: 10.1016/j.bbr.2012.02.031

Pritchard, J.C., Lindberg, A.C., Main, D.C.J., Whay, H.R., 2005. Assessment of the welfare of working horses, mules and donkeys, using health and behaviour parameters. Prev. Vet. Med. 69, 265-283. DOI: 10.1016/j.prevetmed.2005.02.002

Randall, R.P., Schurg, W.A., Church, D.C., 1978. Response of horses to sweet, salty, sour, and bitter solutions. J. Anim. Sci. 47, 51-55.

Rygula, R., Papciak, J., Popik, P., 2013. Trait Pessimism Predicts Vulnerability to StressInduced Anhedonia in Rats. Neuropsychopharmacology 38, 2188-2196. DOI: 10.1038/npp.2013.116

Schelde, J.T.M., 1998. Major depression: Behavioral markers of depression and recovery. J. Nerv. Ment. Dis. 186, 133-140. DOI: 10.1097/00005053-199803000-00001 
Siegrist, J., 2008. Chronic psychosocial stress at work and risk of depression: evidence from prospective studies. Eur. Arch. Psychiatry Clin. Neurosci. 258, 115-119. DOI: $10.1007 / \mathrm{s} 00406-008-5024-0$

Strekalova, T., Spanagel, R., Bartsch, D., Henn, F.A., Gass, P., 2004. Stress-induced anhedonia in mice is associated with deficits in forced swimming and exploration. Neuropsychopharmacology 29, 2007-2017. DOI: 10.1038/sj.npp.1300532

Strickland, P.L., Deakin, J.F.W., Percival, C., Dixon, J., Gater, R.A., Goldberg, D.P., 2002. Bio-social origins of depression in the community - Interactions between social adversity, cortisol and serotonin neurotransmission. Br. J. Psychiatry. 180, 168-173. DOI: $10.1192 /$ bjp.180.2.168

Suomi, S.J., Eisele, C.D., Grady, S.A., Harlow, H.F., 1975. Depressive behavior in adult monkeys following separation from family environment. J. Abnorm. Psychol. 84, 576578. DOI: $10.1037 / \mathrm{h} 0077066$

Swann, W.J., 2006. Improving the welfare of working equine animals in developing countries. Appl. Anim. Behav. Sci. 100, 148-151. DOI: 10.1016/j.applanim.2006.04.001

Tafet, G.E., Bernardini, R., 2003. Psychoneuroendocrinological links between chronic stress and depression. Prog. Neuropsychopharmacol. Biol. Psychiatry 27, 893-903. DOI: $10.1016 / \mathrm{S} 0278-5846(03) 00162-3$

Thompson, D.A., Moskowitz, H.R., Campbell, R.G., 1976. Effects of body-weight and foodintake on pleasantness ratings for a sweet stimulus. J. Appl. Physiol. 41, 77-83.

Tilly, S.L.C., Dallaire, J., Mason, G.J., 2010. Middle-aged mice with enrichment-resistant stereotypic behaviour show reduced motivation for enrichment. Anim. Behav. 80, 363373. DOI: 10.1016/j.anbehav.2010.06.008 
Van Ree, J.M., Niesink, R.J.M., Van Wolfswinkel, L., Ramsey, N.F., Kornet, M., Van Furth, W.R., Vanderschuren, L., Gerrits, M., Van den Berg, C.L., 2000. Endogenous opioids and reward. Eur. J. Pharmacol. 405, 89-101. DOI: 10.1016/S0014-2999(00)00544-6

Visser, E.K., Ellis, A.D., Van Reenen, C.G., 2008. The effect of two different housing conditions on the welfare of young horses stabled for the first time. Appl. Anim. Behav. Sci. 114, 521-533. DOI: 10.1016/j.applanim.2008.03.003

Walker, M.D., Mason, G., 2011. Female C57BL/6 mice show consistent individual differences in spontaneous interaction with environmental enrichment that are predicted by neophobia. Behav. Brain Res. 224, 207-212. DOI: 10.1016/j.bbr.2011.06.003

Wang, Z., Goonewardene, L.A., 2004. The use of MIXED models in the analysis of animal experiments with repeated measures data. Canadian J. Anim. Sci. 84, 1-11.

Waring, G., 2003. Horse Behavior, second edition. Noyes Publications/William Andrew Publishing, Norwich, New York.

Willner, P., Muscat, R., Papp, M., 1992. Chronic mild stress-induced anhedonia - A realistic animal-model of depression. Neurosci. Biobehav. Rev. 16, 525-534. DOI: $10.1016 / \mathrm{S} 0149-7634(05) 80194-0$

Wolff, A., Hausberger, M., LeScolan, N., 1997. Experimental tests to assess emotionality in horses. Behav. Processes 40, 209-221. DOI: 10.1016/S0376-6357(97)00784-5

World Health Organisation, 1994. International Statistical Classification of Diseases and Related Health Problems. World Health Organisation, Geneva.

Yeates, J.W., Main, D.C.J., 2008. Assessment of positive welfare: A review. Vet. J. 175, 293300. DOI: $10.1016 /$ j.tvj1.2007.05.009 

in the Diagnostic Manual of Mental Disorders DSM- fifth edition (APA, 2013, pp. 160161).

The DSM is a widely-used diagnostic guide in human psychological medicine and potentially useful for application to non-human animals (Ferdowsian et al., 2011). Approximately every two decades it is revised, reflecting the challenges of identifying forms of illness that are complex and sometimes have no single defining criterion. However, since the DSM-III (APA, 1980) its criteria for depression have been essentially stable, with anhedonia playing a central role. Currently, "five (or more) of the following symptoms have been present during the same 2-week period and represent a change from previous functioning; at least one of the symptoms is either (1) depressed mood or (2) loss of interest or pleasure" (DSM-V p160) ( $\$$ in the table). These symptoms must also not be due to another medical condition, e.g. not better explained by schizophrenia or other psychotic disorders.

\section{\# $\quad$ Symptom description}

Depressed mood most of the day, nearly every day, as indicated by either subjective report

1 (§) (e.g. feels sad, empty, hopeless) or observation made by others (e.g. appears tearful). (Note: in children or adolescents, this can be manifest as irritability.)

Markedly diminished interest or pleasure in all, or almost all, activities most of the day, nearly every day (as indicated by either subjective account or observation) 
Significant weight loss, despite not dieting, or weight gain (e.g. a change of more than $5 \%$

3 of body weight in a month), or a decrease or increase in appetite nearly every day. (Note: in growing children, this may be manifest as failures to make expected weight gain.)

$4 \quad$ Insomnia or hypersomnia nearly every day.

Psychomotor agitation or retardation nearly every day (observable by others: not merely subjective feelings of restlessness or being slowed down).

Common manifestations of psychomotor retardation include "slow speech, thinking

$5(*) \quad$ and body movements; increased pauses before answering; speech that is decreased in volume, inflection, amount, variety of content, or muteness"; and of psychomotor agitation: "the inability to sit still, pacing, hand-wringing, pulling or rubbing of the skin, clothing, or other objects" (DSM-V, p163)

$6 \quad$ Fatigue or loss of energy nearly every day.

Feelings of worthlessness or excessive or inappropriate guilt nearly every day (which may

$7(*)$ be delusional; and are beyond mere self-reproach or guilt about being sick).

Diminished ability to think or concentrate, or indecisiveness, nearly every day (assessed 8 either via subjective self-report or as observed by others).

$9(*)$

Recurrent thoughts of death (not just fear of dying), recurrent suicidal ideation without a specific plan, or a suicide attempt or a specific plan for committing suicide. 
748 Table 2: subjects' characteristics: age, sex and whether they previously have been (or not) studied in the Fureix's et al (2012) study

750

\begin{tabular}{|c|c|c|c|}
\hline Horse ID & Age (years) & Sex & Previously studied? \\
\hline 1 & 20 & Female & Yes \\
\hline 2 & 18 & Gelding & Yes \\
\hline 3 & 17 & Female & Yes \\
\hline 4 & 16 & Gelding & Yes \\
\hline 5 & 16 & Gelding & Yes \\
\hline 6 & 15 & Gelding & Yes \\
\hline 7 & 15 & Gelding & Yes \\
\hline 8 & 14 & Gelding & Yes \\
\hline 9 & 18 & Gelding & Yes \\
\hline 10 & 18 & Gelding & Yes \\
\hline 11 & 17 & Gelding & Yes \\
\hline 12 & 17 & Gelding & Yes \\
\hline 13 & 16 & Gelding & Yes \\
\hline 14 & 14 & Gelding & Yes \\
\hline 15 & 13 & Gelding & Yes \\
\hline 16 & 8 & Gelding & No \\
\hline 17 & 15 & Female & No \\
\hline 18 & 7 & Gelding & No \\
\hline 19 & 9 & Female & No \\
\hline 20 & 7 & Gelding & No \\
\hline
\end{tabular}




\begin{tabular}{ll}
\hline Name & Description \\
\hline Crib-biting & The horse grasps a fixed object with its incisors, pulls back, \\
& and draws air into its oesophagus while emitting a \\
& characteristic pharyngeal grunt.
\end{tabular}

Lip play

The horse moves its upper lip up and down without making contact with an object, or the horse smacks its lips together (three movements or more in a bout).

Tongue play The horse sticks out its tongue and twists it in the air (three movements or more in a bout).

Lip or teeth rubbing The horse rubs its upper lip or its upper teeth repetitively against the box wall (three movements or more in a bout).

Weaving The horse sways laterally, moving its head, neck, forequarters, and sometimes hindquarters (three movements or more in a bout).

Head shaking and nodding The horse bobs repetitively its head up and down or tosses its head in recurrent and sudden bouts (three movements or more in a bout). 
757 Figure 1: The posture of "withdrawn" horses. Pictures of a horse a) in a withdrawn posture,

b) standing observing and c) standing resting. The withdrawn state is characterized by a stretched neck (obtuse jaw-neck angle) and a similar height between the horse's neck and back (a nape-withers-back angle of $\approx 180^{\circ}$ ). This posture is different from those associated with observation of the environment (for which the neck is higher), and resting, when eyes are at least partly closed and the horse's neck is rounder (Waring, 2003; Fureix et al., 2011b). Note that the restricted size of the stall $(3 \mathrm{~m} \times 3 \mathrm{~m})$ prevented the authors from taking a picture of the whole horse displaying the withdrawn posture, as we chose to use the same lens to limit shape distortion between images.

Figure 2. Relationship between the time spent being withdrawn and sucrose intake, controlling for age, sex and time spent in the stall (thus able to eat the sugar) over testing. Black diamonds: after $3 \mathrm{~h}$ of exposure; dark grey squares: after $8 \mathrm{~h}$ of exposure; lighter grey triangles: after $24 \mathrm{~h}$ of exposure; lightest grey crosses: after $30 \mathrm{~h}$ of exposure.

Figure 3. Relationship between the time spent being withdrawn and sucrose intake, controlling for age, sex and time spent in the stall, hay consumption and latency to eat a meal of normal pellets scented with novel aromatics. Black diamonds: after $3 \mathrm{~h}$ of exposure; dark grey squares: after $8 \mathrm{~h}$ of exposure; lighter grey triangles: after $24 \mathrm{~h}$ of exposure; lightest grey crosses: after $30 \mathrm{~h}$ of exposure. 
Angle nape - withers - back $=180^{\circ}$

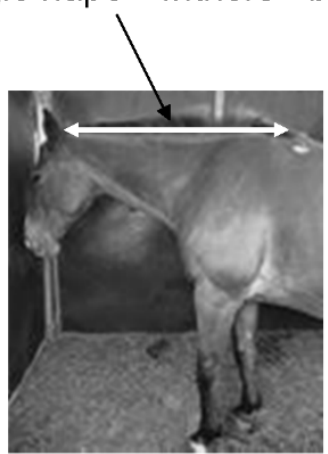

a) "withdrawn"

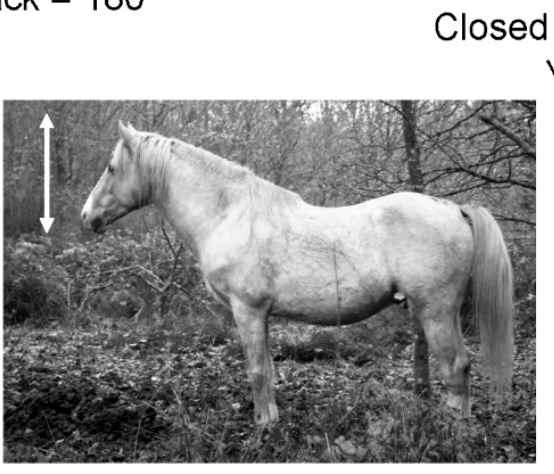

b) standing observing
Closed or parlty closed eyes

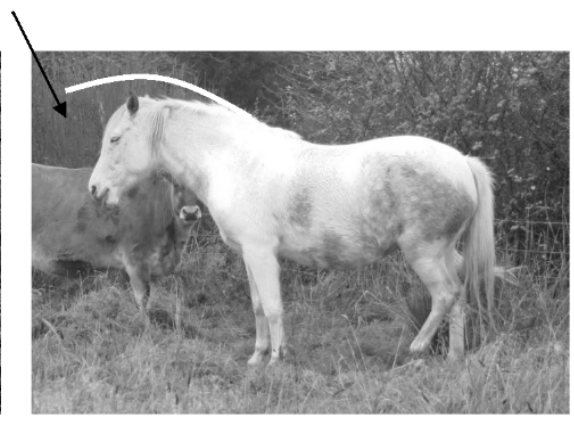

c) standing resting 
Least square mean proportion of
sugar the horse ate out of the $600 \mathrm{~g}$ (arc-sine square root transformed)

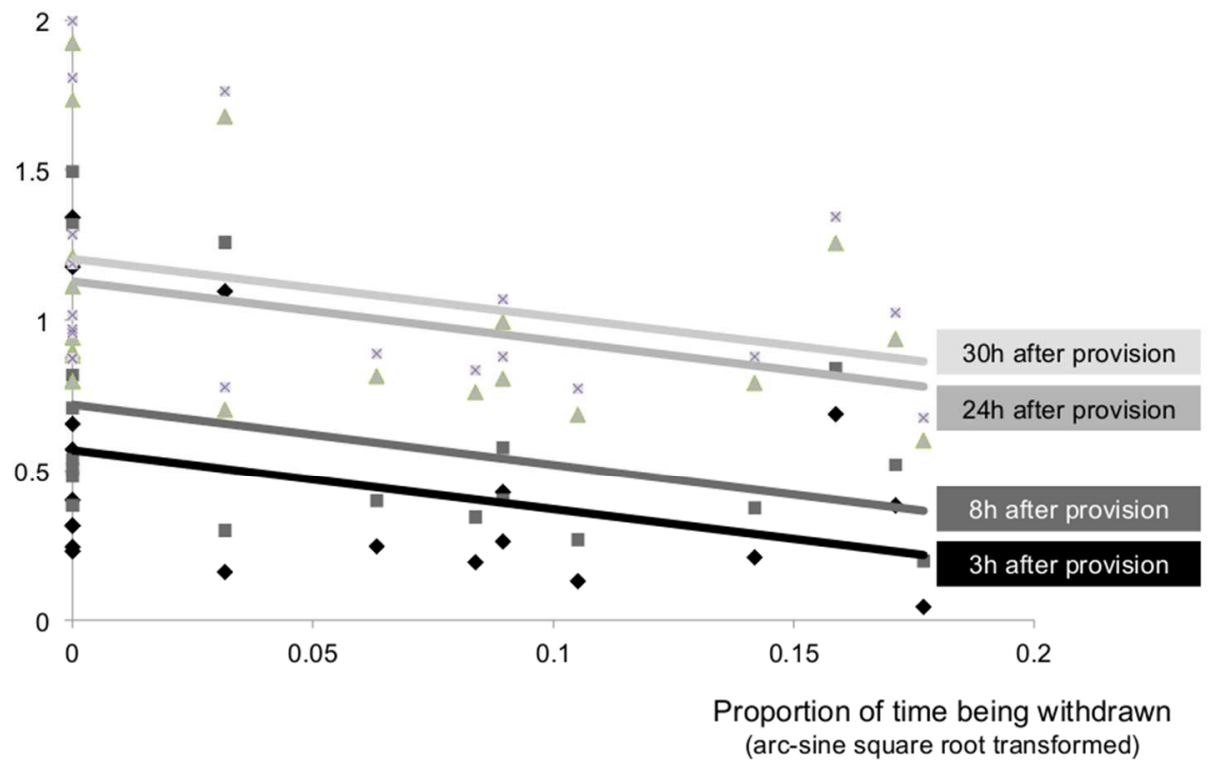


Least square mean proportion of sugar the horse ate out of the $600 \mathrm{~g}$

(arc-sine square root transformed)

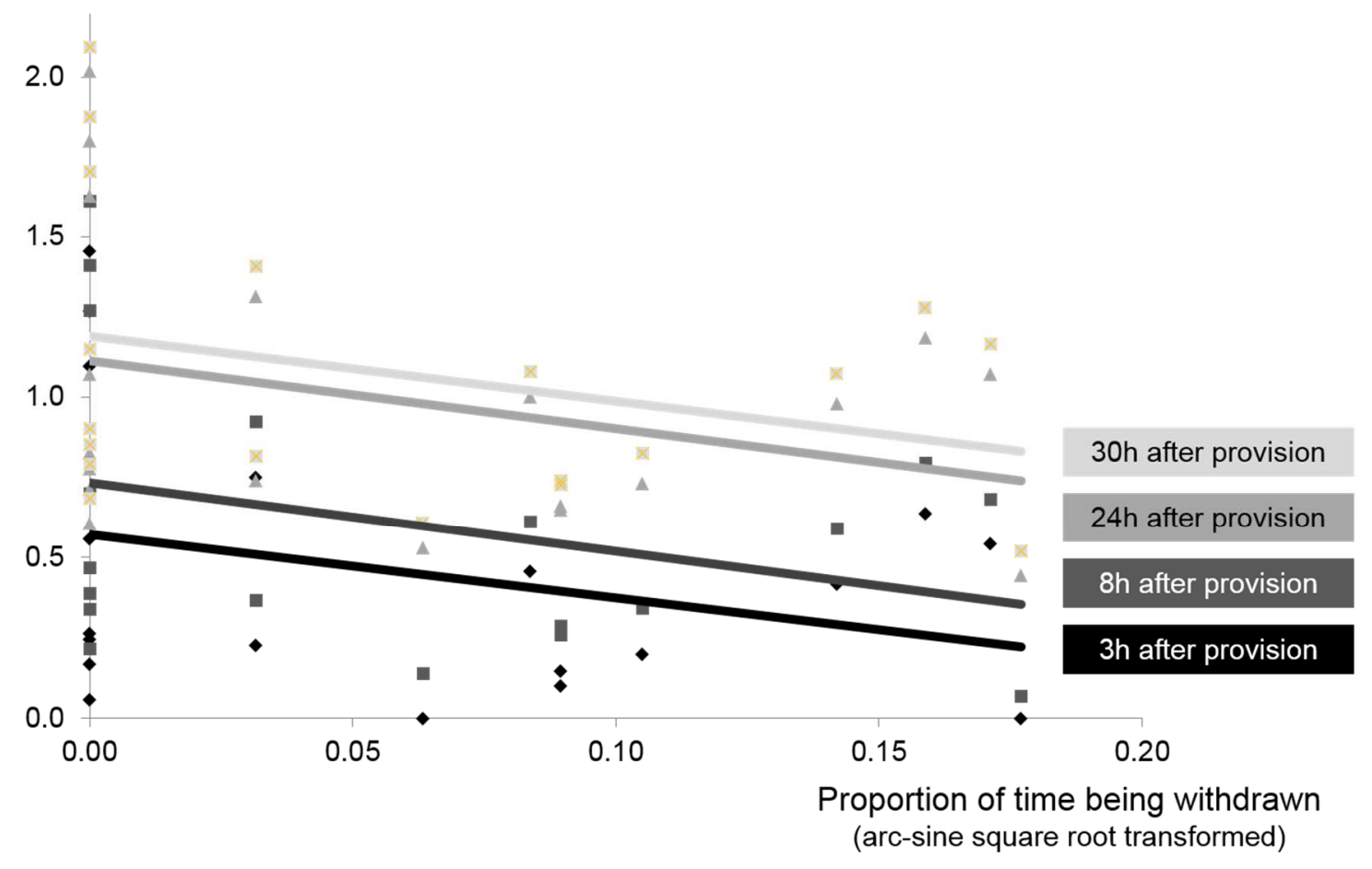

